\title{
Breast cancer survivors' barriers and motives for participating in a group-based physical activity program offered in the community
}

\author{
Amanda Wurz • Anik St-Aubin • Jennifer Brunet
}

Received: 26 July 2014 / Accepted: 29 December 2014 /Published online: 22 January 2015

(C) The Author(s) 2015. This article is published with open access at Springerlink.com

\begin{abstract}
Purpose The purpose of this qualitative study was to explore the barriers and motives experienced by women attending an 8 -week group-based physical activity program offered in the community following treatment for breast cancer.

Methods Seven women were interviewed during the first and last week of the program. Data were analyzed using thematic analysis.

Results Factors that hindered women's continued participation could be subdivided into situational barriers, which encompassed community (i.e., distance of center and traffic) and institutional factors (i.e., competing roles and responsibilities), and internal barriers, which consisted of cancerspecific limitations. Motives for initial and continued participation were situational (i.e., gaining social support, networking, and being around similar others) and internal (i.e., feeling a sense of personal fulfillment, acquiring health benefits, and recovering from cancer).

Conclusions The findings contribute to a deeper understanding of women's motives to engage in a group-based physical activity program after treatment for breast cancer. Further, they underscore the necessity of considering situational and internal barriers when developing group-based physical activity programs to increase regular participation, optimize adherence, and reduce drop-out.
\end{abstract}

Keywords Group-based physical activity · Breast cancer . Survivorship · Qualitative study · Community-based

A. Wurz $\cdot$ A. St-Aubin $\cdot$ J. Brunet $(\bowtie)$

School of Human Kinetics, University of Ottawa,

125 University Private, Montpetit Hall, Room 339,

Ottawa, ON K1N 6N5, Canada

e-mail: jennifer.brunet@uottawa.ca
Breast cancer is the most common cancer in women, with nearly 1.7 million new cases diagnosed in 2012 [1]. Advances in early detection and treatment protocols have resulted in declining mortality rates, with eight out of ten women living for at least 5 years after their cancer is diagnosed [2]. Although imperative for recovery, conventional treatments such as surgery, chemotherapy, radiation, and hormone therapy are associated with a myriad of adverse psychosocial (e.g., mood, depression, anxiety, social isolation, lack of perceived social support) and physical side effects (e.g., musculoskeletal limitations, weight gain, cardiopulmonary impairments) [2-4]. In addition, women diagnosed with breast cancer are at an increased risk of comorbid conditions (e.g., metabolic syndrome, heart diseases) and secondary malignancies as a result of their cancer and its treatments [5-7].

Physical activity has emerged as a key strategy to help mitigate the negative psychosocial and physical side effects of cancer and its treatments, reduce the risks of comorbidities and secondary malignancies, and improve overall quality of life [8-11]. Based on the evidence for the beneficial effects of physical activity, guidelines have recently been developed for women affected by breast cancer [12]. The guidelines suggest that women engage in aerobic (30 min, 3 times per week), resistance (6-12 exercises, 2-3 times per week), and flexibility training (50-60 min, 3 times per week). Unfortunately, studies have shown few women meet these guidelines after completing treatment for breast cancer $[13,14]$. This is a serious health concern since physical inactivity increases the risks of disability, morbidity, and mortality [15]. Thus, the known benefits of physical activity, in conjunction with low levels reported, underscore the necessity of developing programs to help promote physical activity initiation and maintenance in this population.

Group-based physical activity programs may be an ideal way to help women accumulate physical activity after 
treatment for breast cancer. Research shows that group-based physical activity programs are not only an effective strategy to promote physical activity $[16,17]$, but confer additional psychosocial and physical health benefits [17-20]. In light of this evidence, researchers have developed and tested different types of group-based physical activity programs such as dragon boating [21], yoga [22], aerobic exercise classes [16], and mountain climbing [23]. By taking part in these programs, participants can increase their overall physical activity levels, while gaining psychosocial (e.g., quality of life, support from others) and physical health benefits (e.g., fitness improvements; $[8,10,19,24])$. Although group-based physical activity programs appear to be beneficial, high drop-out rates have been observed [25]. Thus, research into the factors that hinder and promote sustained participation is important to enable the modification of current programs to increase regular participation, optimize adherence, and reduce drop-out.

Barriers are obstacles that can interfere with behaviour initiation and maintenance [26]. Based on social cognitive theory [27], barriers can be grouped based on whether they relate to the situation (i.e., situational barriers) or the individual (i.e., internal barriers). Situational barriers are factors outside of an individual's internal control that may prevent or limit participation in physical activity [28]. These can be interpersonal (e.g., lack of social support; [29]), institutional (e.g., competing caretaking roles; [30]), community (e.g., lack of access to facilities, far distance to the place of practice; [31]), public policy (e.g., no bicycles allowed on sidewalks; [32]), or physical environment characteristics (e.g., bad weather; [33]). Internal barriers are synonymous with intrapersonal barriers and reflect the biological events and internal thoughts, cognitions, and emotions that people identify as reasons why participating in physical activity is difficult [28]. Examples are fatigue, fear of injury, poor physical condition, and lack of motivation, knowledge, and enjoyment $[34,35]$. Based on previous research, women perceive a myriad of situational (e.g., lack of time, bad weather, limited access to facilities) and internal barriers (e.g., fatigue, lack of motivation, fear of injury, lack of enjoyment, failure to identify as an exerciser, functional limitations, cancer treatments, co-morbidities) that negatively affect their ability to initiate or maintain self-directed physical activity post treatment for breast cancer [36-38].

In addition to barriers identified in the literature, researchers have also investigated factors that facilitate physical activity initiation and maintenance (e.g., [39]) such as motives. Motives refer to the outcomes or states that an individual aims to attain or avoid [40], and are inherent within several theories (e.g., social cognitive theory; [27]). Examples of motives include disease management, improving physical fitness, promoting psychological well-being, and acquiring social support [41, 42]. Women have identified several motives for participating in physical activity post treatment for breast cancer. For example, improved body image, enjoyment, positive emotions, social support, weight management, health management, and increased energy have been commonly reported $[37,43]$. Considering the categorization of barriers presented above, these motives can be broadly categorized as either situational as they relate to what the situation can offer (e.g., social support) or internal as they relate to the individual and reflect physical outcomes and internal thoughts, cognitions and emotions people identify as reasons for participating in physical activity (e.g., improved body image, enjoyment; [28]).

Although previous studies have contributed to the understanding barriers and motives for physical activity, none have examined these factors within the context of a group-based physical activity program offered within a community setting. In light of the increasing popularity of group-based physical activity programs offered in the community through cancer survivorship centers, the purpose of this qualitative study was to describe women's barriers and motives for attending an 8-week group-based physical activity program at the Maplesoft Centre for Cancer Survivorship Care after being diagnosed with breast cancer. This knowledge can be used to help optimize the design and implementation of physical activity programs to reduce the cancer burden and improve women's health and well-being in the aftermath of breast cancer.

\section{Materials and methods}

\section{Participants}

Women were recruited from the Maplesoft Centre for Cancer Survivorship Care. Inclusion criteria were women who were (a) post treatment for breast cancer, (b) over 18 years of age, (c) English-speaking, (d) registered in the 8-week group-based physical activity program offered at the center during the Fall of 2013, (e) able to provide informed consent, and (f) willing to take part in two face-to-face interviews.

\section{Procedures}

Following approval from the University Research Ethics Board and permission from the staff at the Maplesoft Centre for Cancer Survivorship Care, the second author attended the first class of the 8-week group-based physical activity program offered during the Fall of 2013. The main goal of the program was to promote physical activity by having individuals diagnosed and/or treated for cancer take part in two physical activity classes per week. The program had 17 registered participants and was led by a trained fitness instructor. Moreover, the classes were structured to accommodate participants with differing fitness and skill levels and offered free-of-charge. 
The second author introduced the study at the end of the first class to the ten participants who attended the class that day. She described the study, outlined eligibility criteria, and invited interested participants to contact her. Six of the ten participants who attended the class contacted her. She also placed study posters throughout the center, which resulted in the recruitment of one additional participant. In total, seven women volunteered, met eligibility criteria, and provided written informed consent to participate in this study.

Participants completed a brief demographic form and were interviewed by the second author within one week of the first class, and again at program completion (approximately 8 weeks later). Of note, one participant did not complete the follow-up interview, as she could not be contacted after three attempts. The interviews were semi-structured and conducted in a private room at the University of Ottawa or in a private room at the Maplesoft Centre for Cancer Survivorship Care during mutually agreed upon times and dates. Interviews lasted between 24 and $50 \mathrm{~min}$ and were audio-recorded.

\section{Data collection instruments}

Demographic questionnaire Before starting the interview, participants completed a brief demographic questionnaire to provide information pertaining to their age, educational attainment, annual household income, employment status, and ethnicity.

Interviews Interviews were guided by an interview schedule containing a series of open-ended questions and probes to encourage participants to provide more detail or clarify what they were saying. In addition, the second interview served to verify the information from their first interview, and potentially elucidate new barriers and motives after participants had completed the program. The interview guide for the first and second interviews were similar and centered on participants' barriers (e.g., "What are/were some barriers that you've encountered while trying to maintain your participation in this program?") and motives for participating in the program (e.g., "Tell me about the reasons why you participate in this program."). Questions regarding participants' perceptions of the program environment and instructor were also asked. The analyses of themes and subthemes relating to both the environment and instructor are presented elsewhere.

Self-reported attendance During the second interview, participants reported the number of classes they missed. This information was then used to calculate attendance by subtracting the number of classes missed from the total sessions offered $(N=16)$.
Data analysis

The second author transcribed the recorded interviews verbatim. Then, each transcript was analyzed by the first author following the flexible set of guidelines for thematic analysis outlined by Braun and Clark [44]. This method of analysis was selected as it allowed for the search of themes that were important to describe the phenomenon under study [44], namely barriers and motives for participation in a cancerspecific group-based physical activity program offered in the community. In this step-by-step process of analysis, the first author read each transcript several times to become familiarized with the data. Next, salient features within each interview were identified to generate initial codes. Salient features were determined based on their relevance to the research question and by researcher judgment. Third, similar codes were grouped together into subthemes, and organized into main themes that summarized the raw data and conveyed the salient themes. At this point, the second and third author performed member checks by reviewing the themes to check for internal homogeneity (i.e., data within themes fit together meaningfully) and external heterogeneity (i.e., clear distinctions between themes). In cases of disagreement, all authors discussed until consensus was reached. Once this was established, a description of the meaning of each of the themes was developed. Last, representative quotes were selected from the transcripts to illustrate each theme. Women's names were changed to pseudonyms to protect their anonymity.

To ensure the quality and credibility of findings, various strategies recommended in the literature were used [45]. First, a sample that shared the common experience of breast cancer and participating in a group-based physical activity class at the Maplesoft Centre for Cancer Survivorship Care was selected. Second, member checks took place. This fostered a critical dialogue that encouraged reflection, exploration, and discussion. Moreover, it sought to substantiate the results in an unbiased and independent manner. Third, detailed descriptions of themes were included and verbatim quotes were selected from the raw data to illustrate the meaning of the themes and exemplify how data were interpreted. Fourth, a second interview was performed to allow participants to verify and comment on the interpretations of data gathered, as well as provide additional information regarding their experiences.

\section{Results}

Participants

In addition to undergoing surgery, the seven women who participated in this study had received either a combination of chemotherapy, radiation, and hormonal therapy $(n=4)$, 
radiation and hormonal therapy $(n=2)$, or hormonal therapy $(n=1)$. While data on treatment dates were not explicitly collected, all women reported they had completed treatment within the previous few months during the first interview. The mean age of the sample was 55.3 years, six of the seven women self-identified as Caucasian, the other self-identified as West Asian. Two of the women were working full-time, two were currently on disability and had plans to return to work, and the remaining three were currently unemployed or retired. Based on self-reported recall, attendance to the 8-week program ranged from $69 \%$ (11/16 classes) to $100 \%$.

The thematic analysis offered an understanding of the women's barriers and motives to engaging in group-based physical activity. Barriers and motives identified were each classified as either situational or internal. Themes and subthemes are presented in Table 1, and described in the following section along with relevant quotes.

\section{Barriers}

Situational and internal barriers to participating in groupbased physical activity were identified. The situational obstacles included community and institutional factors. Internal obstacles pertained to cancer-specific limitations. The barriers women identified in the first interview were affirmed during the second interview, and no additional barriers were mentioned.

\section{Situational barriers}

\section{Community: distance of center and traffic}

The geographic location of the centre was identified as a significant barrier because it was distant from women's homes. They discussed that having to drive to the centre reduced their ability to attend certain classes offered. For instance, Lynne mentioned: "I think the biggest barrier is the drive down, and the fact that it's twice a week. I mean I understand why it's twice a week, but it's twice a week that I have to come all the

Table 1 Barriers and motives to participation in group-based physical activity

\begin{tabular}{ll}
\hline Barriers & Motives \\
\hline Situational & Situational \\
Institutional & Interpersonal \\
$\bullet$ Competing roles and responsibilities & $\bullet$ Receiving social support \\
$\begin{array}{l}\text { Community } \\
\text { • Distance of center }\end{array}$ & $\bullet$ Networking \\
$\begin{array}{l}\text { Traffic } \\
\text { Internal }\end{array}$ & Being around similar others \\
$\bullet$ Cancer-specific limitations & $\bullet$ Personal fulfillment \\
& $\cdot$ Acquiring health benefits \\
& $\cdot$ Recovering from cancer \\
\hline
\end{tabular}

way down here." She went on to talk about how she only registered for classes offered when there is likely to be no traffic: "I don't take anything here that's past 2:00 pm because of traffic." Similarly, Patricia illustrated the burden of the drive to the centre by saying: "In my capacity at the moment, sometimes driving is very hard. Sometimes I just don't want to drive. That is one barrier." Women also indicated that in addition to disliking the drive, they disliked not knowing if there would be available parking spots. Roxanne recounted: "Barriers are not liking to drive there, and when you get there and there's no parking spots." She went on to mention how she had to "plan for it" by making sure she arrived extra early, which increased the time she needed to attend the 1-hour class.

\section{Institutional: competing roles and responsibilities}

Scheduling conflicts as well as having other commitments and responsibilities were key factors that influenced women's ability to attend classes. Evelyn noted that when she was working, she could only attend when she had time off. She stated: "Unfortunately, I had to go back to work and because they [groupbased physical activity classes] were during the day, when I had the day off I would go over to the exercise classes." She noted, however, that she was recently retired and that the timing of the class no longer made a difference for her personally. Similarly, Roxanne, who was employed full-time considered that having to work interfered with her participation because of the times when classes are generally offered: "It's right in the middle of the day. Like it's fine if you're off work, but I see that being a big barrier for people who are working like me."

In addition to identifying work conflicts, women felt that other commitments and responsibilities they had interfered with their ability to attend two classes each week. Patricia, who was employed full-time, admitted that she felt overwhelmed at times:

Women have multiple tasks and multiple jobs so something is going to be dropped. Something related to us... Most of the time, that's the issue that everybody is talking about because we are not able to take care of ourselves anymore. That, I think this is another barrier.

Lynn echoed this sentiment stating: "It's two times a week. You think 'that's not a lot', but with everything else that is happening in my life, this is a huge commitment." As well, women noted that ongoing medical appointments conflicted with their classes, which was another reason for missing classes. Elizabeth, who was preparing to return to work after being on disability for her diagnosis and treatments, stated:

I'm going back to work so there are many appointments, which unfortunately interfere... I don't have the time to set this [group-based physical activity program] as the 
highest priority. You know, for example, there will be a spot open for an MRI that conflicts, and I want to do the MRI and mammography before I go back to work. So yeah, that's unfortunate, it shouldn't be like that, but right now it's all about work and going back.

\section{Internal barriers}

\section{Cancer-specific limitations}

Women mentioned that limitations related to their cancer diagnosis, treatments, and side effects interfered with their ability to attend classes. Specifically, they discussed the obstacles posed by being sick. Elizabeth shared that it was sometimes difficult for her to attend some classes "because I was so sick." Interestingly, women further explained that having flu- or cold-like symptoms were barriers, insofar as they avoided the class to protect other participants who may have weakened immune systems while undergoing treatment. As Evelyn mentioned:

I had a very bad cold so I did not come to the exercise classes because we have patients, participants who are doing treatment, chemo and radiation and are going to have surgery or just had surgery. So there's no way I'll come if I'm sick because I know how I felt when I was in that position and somebody came to class and was sniffling and started sneezing, and coughing. I was just like nope gotta leave.

While some side effects of cancer and its treatments such as the physical limitations caused by surgery did not prevent them from going to class, they were discussed as a barrier to women's ability to complete certain activities in the classes. Ellen considered the physical changes that happened after surgery: "Because I've had breast cancer, I have had lymph nodes taken out of my arm. It doesn't take much to for that part of the body up to the shoulders to stiffen." She went on to describe having difficulties performing some exercises "I have a hard time doing the plank. That's because this arm is quite weak. I can do the modified version, but not the full version. I am still working on it." In a similar vein, Gisele mentioned the negative effects of being sedentary during treatment, and how this reduced her ability to engage in some of the activities she used to engage in before her diagnosis:

I was in bed for a year, so my muscles and everything just was kind of gone. You know atrophy. I just didn't have any strength. We used to be active skiers all the time but you know the muscles in my thighs were gone, my quads were gone and everything else as well. It took me a little while to get my motor running again.
Overall, women considered situational obstacles to participating in the group-based classes to be related to community (i.e., distance to center and traffic) and institutional factors (i.e., competing roles and responsibilities). Moreover, they considered internal barriers to their participation to include cancer-specific limitations related to their own and others' cancer diagnosis and treatments.

\section{Motives}

Women discussed a variety of motives for participating in the program. They identified factors that could be divided into situational and internal themes. Situational motives were interpersonal in nature and could be further divided into two subthemes: receiving social support and networking, and engaging in physical activity with others affected by cancer. Internal motives could be further divided into three subthemes: feeling a sense of personal fulfillment, acquiring health benefits, and seeing the program as playing a key role in their cancer recovery. Of note, the internal motives women identified only emerged during the second interview.

\section{Situational motives}

\section{Interpersonal: social support and networking}

Women identified the support and encouragement they received from other program participants and the social networking opportunities as important motivators. Gisele exclaimed: "We're each others' cheering partner!" Evelyn echoed this feeling by saying: "I like to participate and see the people and talk with them and get that dose of energy. It's very motivating. It really is. I have never done a formal exercise class before and this is great." Women indicated that the camaraderie and friendships gained were important motives. Simply being able to be with or to meet people was appreciated. Elizabeth noted that with continued participation, she knew she would make new friends in the class: "It's good because you know new people, you share, you make new friends." The benefit of support from other participants was important as Ellen recounted: "It is like a support group...The camaraderie, being with other people."

\section{Interpersonal: being around similar others}

Women were motivated to participate in the program because it provided a place for them to participate in physical activity with others who had also been affected by cancer. As Lynne explained: "I wanted to go somewhere where I'm surrounded by people who've got cancer and so my reasoning was to come here." Patricia spoke of the benefits of the shared experience of cancer. She felt that all of the participants spoke the 
"language of cancer." She further explained: "There is so much similarity in the experience. We know how painful this process is. It's like cancer has it own culture." The importance of engaging in physical activity with similar others was highlighted by Roxanne who stated: "I really feel like although we're all different people, with different cancer, different ages, different everything, that there's that common basis and common reason for being there that just makes it a place where you want to be." Similarly, Gisele enjoyed feeling "part of a community" in which she was not afraid to speak about cancer. She stated: "The nice thing about it is that nobody is afraid to talk about their cancer, and their experiences, their reconstruction. You know you're not alone." This made women feel comfortable and facilitated their continued participation in the program. Similarly, being around others surviving cancer gave them hope, as illustrated by Ellen:

When you have cancer you lay awake at night and everything goes through your mind, everything bothers you, every ache and pain bothers you, you know. Because I have friends who are dying of cancer, being around these women who are mostly doing very well, it just gives you hope. It gives you hope for the future.

Women acknowledged they did not feel comfortable in the community, and preferred participating in physical activity at the Maplesoft Centre for Cancer Survivorship Care. Evelyn illustrated this:

You feel uncomfortable [in the community], whereas it doesn't matter here. I wear sleeves sometimes for some of the classes because I have something strange in my arm [referring to her port]. If you're doing chemotherapy and you walk in with the headscarf on, here you can take it off, or if you're wearing your wig, you can take it off. And it's a sense of freedom when you can do that.

Additionally, they expressed difficulty and embarrassment engaging in physical activity in the community due to changes to their bodies as a result of the treatments. Gisele mentioned:

I'm not comfortable wearing my prosthetic and so when I come here to the Maplesoft Centre for Cancer Survivorship Care, I can dress in a way in which I'm comfortable. So you know I often leave it at home in the drawer, and now there are a lot of other women who started doing the same thing. It's heavy, and it sort of gets in the way when you're trying to do your exercises. I know I wouldn't be participating in any other exercise program if the Maplesoft Centre for Cancer Survivorship Care were not here because that comfort level.
Internal motives

\section{Personal fulfillment}

Among the internal motives identified during the second interview, women explained that they experienced a sense of personal fulfillment as a result of realizing they were capable of doing more than they thought they could. This motivated them to continue participating in the program. Roxanne discussed the self-realization of her physical strength: "I have been pleasantly surprised when I realize how much I can actually do. I keep up better than I would've given myself credit for. There have just been too many limitations lately, so it feels good." Similarly, Lynne recounted: "I feel great after completing one [group-based physical activity class]. There is a sense of personal fulfillment. When I try new moves, and I realize how simple they are. The accomplishment for me is wow, I can do these even at home." This instilled sense of fulfillment inspired women to continue attending the classes.

\section{Acquiring health benefits}

Physical and psychological health benefits were also cited as motives to continue participating in the program - namely improved fitness, muscle tone, muscle strength, mood, and energy levels. During the second interview, women shared how the group-based classes were a place to go to feel good and regain their health. For instance, Gisele mentioned: "You never forget what you went through and you see the progress there and you get to the point where you feel even better than before you were sick." Lynne highlighted the benefits she noticed: "When I start doing the exercise, I feel great. It makes me fit, toned, and have more energy." Similarly, Ellen recounted: "I like the energy feeling when you leave [class]." Conversely, women noticed how they felt when they did not participate. This was highlighted by Evelyn who stated: "I find that I don't have that much get-up-and-go when I don't come to the exercise classes."

\section{Program plays a key role in cancer recovery}

After completing the program, women discussed the important role it played in their cancer recovery by fostering feelings of normality and allowing them to feel a sense of self-control. Roxanne mentioned that participating in the program made her feel "more like a normal person and less like a cancer patient." Gisele explained that it made her "feel almost normal again" and was "a great way to transition yourself from being an ill patient to a well person." Regarding feelings of control, Roxanne recounted how participating in the program had given her a feeling of control over her life: "It makes me feel like I am doing something about my own situation and that is something that is lacking when you finish your treatments. It is that 
feeling of doing something for yourself and your health." This sense of control was reiterated by Evelyn who felt that taking part in the program was "my way of doing something about it [cancer]" and by Elizabeth who said "we are doing something actively to overcome the fatigue or the depression or the medication." Patricia mentioned that she felt her ability to complete the program was crucial to her recovery and survivorship stating "this [group-based physical activity program] is medication for me."

Overall, women considered situational motives to participating in the group-based classes which were related to interpersonal factors, including receiving social support and networking, and engaging in physical activity with others diagnosed and/or treated for cancer. Moreover, they considered internal motives to participating in the program, which included feeling a sense of personal fulfillment, acquiring health benefits, and feeling as though it played a key role in their cancer recovery.

\section{Discussion}

Ensuring that women maintain an active lifestyle after being diagnosed and treated for breast cancer is crucial to minimize the negative side effects of treatments, reduce the risks of secondary cancers and comorbidities, and promote quality of life [8-11]. In light of recent trends to offer group-based physical activity programs to people with cancer in the community, studies focused on improving participation and adherence to such programs are important to optimize the associated benefits. Therefore, the purpose of this qualitative study was to explore women's barriers and motives to participating in an 8-week group-based physical activity program offered within a community setting after having completed treatment for breast cancer. Overall, findings revealed that women identified situational (i.e., distance to center, traffic, and competing roles and responsibilities) and internal barriers (i.e., cancerspecific limitations). They also revealed situational (i.e., social support, networking, and being around similar others) and internal motives (i.e., feelings of a sense of personal fulfillment, acquiring benefits, and noticing the program playing a key role in their cancer recovery) for engaging in the group-based program. These findings extend previous research conducted with women treated for breast cancer by identifying barriers and motives specifically for group-based physical activity programs being offered in the community. Program developers might benefit from these findings, as they provide valuable information into the possible mechanisms that underpin women's reasons for participation in such programs, as well as for dropping out.

In this study, situational barriers emerged in that they related to aspects directly associated with the program such as distance of center and traffic. Based on previous categorizations of barriers [28], these were categorized as community and institutional factors. These are consistent with previous research findings reported with both the general population [46] and people with cancer $[37,47]$. This suggests that program developers should determine the feasibility of partnering with other facilities to offer this type of program in different quadrants of the city. Moreover, programs should be offered at a variety of times on a variety of days in an effort to take into account the competing roles and responsibilities that program participants may have.

Internal barriers also appeared in women's descriptions of what impeded their participation. They discussed how being ill because of their cancer or general illness (e.g., cold, flu) was a barrier as it reduced their energy levels and increased their concern about making other program participants sick. While it is important to recognize that women may have reduced energy during these periods or are staying home to protect other participants is respectful, women still recognized the importance of staying active. Thus, it would be valuable to offer women home-based alternatives that require less energy expenditure (e.g., restorative yoga, gentle stretching, mild aerobic activity). Additionally, given the evidence for the efficacy of accumulating physical activity intermittently to acquire health benefits [12], women should be informed about this strategy since shorter bouts may be easier for them to do than longer continuous physical activity when they are not feeling well.

The physical side effects associated with breast cancer and its treatments have been shown to negatively impact women's ability to engage in physical activity $[37,48]$. Similarly, women in this study noted the effects of their cancer and treatments on their physical status. While physical limitations have been reported in populations without a history of cancer, namely older adults [49], some of the physical limitations identified herein are likely unique to this population (e.g., weakened upper body as a result of surgery). Consequently, it is important for health and fitness professionals working with women diagnosed and/or treated for breast cancer to acknowledge these limitations, and provide opportunities for them to modify activities and build capacity within their limitations. The implementation of physical activity programs that show women how to adapt activities to their ability level may help address this physical limitations barrier, and in turn enhance continued participation.

In addition to identifying salient situational and internal barriers, this study also elucidated different situational motives women had for engaging in a group-based physical activity program. Several of these related to how the group feature of the program fostered social support and networking, and allowed them to engage in physical activity with similar others. Other studies have highlighted the importance of obtaining social support and feeling connected to others as motives for physical 
activity [50-53]. Thus, it seems that physical activity, group-based physical activity specifically, may be an ideal setting for women to have their social needs met because of the opportunities that exist for interacting with others. Considering that social support has been identified as a positive determinant of physical activity [50], it would be beneficial to continue offering cancer-specific group-based physical activity programs that integrate opportunities to build a caring social network.

Women also reported a number of internal motives such as feeling a sense of personal fulfillment, acquiring physical and psychosocial benefits, and acknowledging the important role of the group-based physical activity program in their cancer recovery. Of note, these motives emerged only during the second interview after women had completed the program. This may suggest women had to experience these to perceive them as motives for continuing their participation in the program. These findings therefore support the importance of promoting internal motives for continued physical activity participation. Additionally, they substantiate previous research that reported on motives for physical activity such as wanting to gain a sense of personal fulfillment $[16,18,54]$, acquiring psychological and physical benefits $[20,55,56]$, and recovering from cancer [54]. Accordingly, programs should go beyond focusing on physical activity and provide opportunities for participants to focus on the benefits they provide.

\section{Limitations and considerations}

The limitations of this study should be taken into account. Seven of the 17 women who self-enrolled in the 8-week group-based physical activity program were interviewed; it is therefore possible that additional themes and subthemes may have emerged if the other participants were included in this study. Relatedly, the sample consisted of primarily Caucasian women with a mean age of 55.3 years who had completed treatment for breast cancer. It would be informative to investigate if the same themes would emerge across different diagnoses, ethnicities, age ranges, and treatment statuses (e.g., after diagnosis, during treatment). Moreover, exploring different types of physical activity programs (e.g., aerobic versus yoga), longer programs (i.e., $>8$ weeks) and including longer follow-ups post program could provide meaningful information. Finally, researchers could utilize mixed-methods and employ validated existing questionnaires (e.g., European Organization for Research and Treatment of Cancer-Breast Module, Quality of Life in Adult Cancer Survivors Scale, Charlson Comorbidity Index) to explore the associations between health related quality of life and comorbidities and the identified barriers and motives.

\section{Conclusions}

Given the low rates of physical activity reported in women diagnosed and treated for breast cancer [13, 14] and high rates of drop-out reported in group-based physical activity programs [25], research into women's barriers and motives to engage in group-based physical activity programs offered within the community is timely and relevant. Although a fair amount of literature providing evidence of the barriers and motives to physical activity in general is available, there is little evidence that looks at the context-specific barriers and motives such as those for group-based physical activity programs. This qualitative investigation is the first study to seek a deeper understanding of factors that hinder and promote women's participation in a group-based physical activity program following treatment for breast cancer. Both situational (i.e., distance to center, traffic, competing roles and responsibilities) and internal barriers (i.e., cancer-specific limitations) could help explain the reasons for low adherence, whereas motives that are interpersonal (i.e., gaining social support and networking, engaging in physical activity with other cancer survivors) and internal (i.e., feelings of personal fulfillment, acquiring benefits, recovering from cancer) in nature, could explain why women continued participating. These findings can be used to promote the development, implementation, and evaluation of more programs to optimize participation in group-based physical activity and foster positive health and well-being in this population. They can also be used to inform future research, in that researchers may want to test the associations between these barriers and motives and class attendance using quantitative and/or mixed methods.

Acknowledgments The authors would like to thank all of the women who participated in the study and shared their experiences in the program. The authors would like to thank the staff at the Maplesoft Centre for Cancer Survivorship Care for their support of this research. This manuscript was prepared while the Jennifer Brunet was supported by a Canadian Cancer Society Career Development Award in Prevention.

Conflict of interest The authors have no conflicts of interest or financial disclosures to report.

Open Access This article is distributed under the terms of the Creative Commons Attribution Noncommercial License which permits any noncommercial use, distribution, and reproduction in any medium, provided the original author(s) and the source are credited.

\section{References}

1. Jemal A, Bray F, Center MM, Ferlay J, Ward E, Forman D (2011) Global cancer statistics. CA Cancer J Clin 2:69-90

2. Siegel R, DeSantis C, Virgo K, Stein K, Mariotto A, Smith T, Cooper D, Gansler T, Lerro C, Fedewa S et al (2012) Cancer treatment and survivorship statistics. CA Cancer J Clin 62:220-241 
3. Ganz PA, Kwan L, Stanton AL, Bower JE, Belin TR (2011) Physical and psychosocial recovery in the year after primary treatment of breast cancer. J Clin Oncol 29(9):1101-1109

4. Compas BE, Lueken L (2002) Psychological adjustment to breast cancer. Curr Dir Psychol Sci 11(3):111-114

5. Hooning MJ, Botma A, Aleman BM, Baaijens MH, Bartelink H, Klijn JG, Taylor CW, van Leeuwen FE (2007) Long-term risk of cardiovascular disease in 10-year survivors of breast cancer. J Natl Cancer Inst 99(5):365-375

6. Matesich SM, Shapiro CL (2003) Second cancers after breast cancer treatment. Semin Oncol 30(6):740-748

7. Protani M, Coory M, Martin JH (2010) Effect of obesity on survival of women with breast cancer: systematic review and meta-analysis. Breast Cancer Res Treat 123(3):627-635

8. Ballard-Barbash R, Friedenreich CM, Courneya KS, Siddiqi SM, McTiernan A, Alfano CM (2012) Physical activity, biomarkers, and disease outcomes in cancer survivors: a systematic review. J Natl Cancer Inst 104(11):815-840

9. Loprinzi PD, Cardinal BJ (2012) Effects of physical activity on common side effects of breast cancer treatment. Breast Cancer 19(1):4-10

10. Schmitz K (2011) Physical activity and breast cancer survivorship. Recent Results Cancer Res Fortschr Krebsforschung Progres dans les Rech sur le Cancer 186:189-215

11. Mishra SI, Scherer RW, Geigle PM, Berlanstein DR, Topaloglu O, Gotay CC, Snyder C (2012) Exercise interventions on health-related quality of life for cancer survivors. Cochrane Database Syst Rev 8, CD007566

12. Brunet J, Sabiston CM, Meterissian S (2012) Physical activity and breast cancer survivorship: evidence-based recommendations. Am J Life Med 6:224-240

13. Harrison S, Hayes SC, Newman B (2009) Level of physical activity and characteristics associated with change following breast cancer diagnosis and treatment. Psycho-Oncology 18:387-394

14. Irwin ML, McTiernan A, Bernstein L, Gillilan FD, Baumgartner R, Baumgartner K, Ballard-Barbash R (2004) Physical activity levels among breast cancer survivors. Med Sci Sports Exerc 36:1484-1491

15. Lynch BM (2010) Sedentary behavior and cancer: a systematic review of the literature and proposed biological mechanisms. Cancer epidemiology, biomarkers \& prevention: a publication of the American Association for Cancer Research, cosponsored by the American Society of Preventive Oncology, 19(11):2691-2709

16. Emslie C, Whyte F, Campbell A, Mutrie N, Lee L, Ritchie D, Kearney N (2007) 'I wouldn't have been interested in just sitting round a table talking about cancer'; exploring the experiences of women with breast cancer in a group exercise trial. Health Educ Res 22(6):827-838

17. Rajotte EJ, Yi JC, Baker KS, Gregerson L, Leiserowitz A, Syrjala KL (2012) Community-based exercise program effectiveness and safety for cancer survivors. J Cancer Surviv : Res Pract 6(2):219-228

18. Mutrie N, Campbell AM, Whyte F, McConnachie A, Emslie C, Lee L, Kearney N, Walker A, Ritchie D (2007) Benefits of supervised group exercise programme for women being treated for early stage breast cancer: pragmatic randomised controlled trial. Brit Med J 334: 517-523

19. Naumann F, Munro A, Martin E, Magrani P, Buchan J, Smith C, Piggott B, Philpott M (2012) An individual-based versus groupbased exercise and counselling intervention for improving quality of life in breast cancer survivors. A feasibility and efficacy study. Psycho-Oncology 21(10):1136-1139

20. Sabiston CM, McDonough MH, Crocker PRE (2007) Psycho-social experiences of breast cancer survivors involved in a dragon boat program: exploring links to positive psychological growth. J Sports Exerc Psychol 29:419-438

21. Mitchell T, Nielson E (2002) Living life to the limits: dragon boaters and breast cancer. Can Women Stud 21:50-57
22. Culos-Reed SN, Carlson LE, Daroux LM, Hately-Aldous S (2006) A pilot study of yoga for breast cancer survivors: physical and psychological benefits. Psycho-Oncology 15(10):891-897

23. Burke SM, Sabiston CM (2010) The meaning of the mountain: exploring breast cancer survivors' lived experiences of subjective well being during a climb on Mt.Kilimanjaro. Qual Res Sport Exerc 2: $1-16$

24. Schmitz KH, Holtzman J, Courneya KS, Masse LC, Duval S, Kane R (2005) Controlled physical activity trials in cancer survivors: a systematic review and meta-analysis. Cancer Epidemiol Biomarkers Prev 14:1588-1595

25. Craig CL, Russell SL, Cameron C, Beaulieu A (1999) Foundation for joint action: reducing physical inactivity. Canadian Fitness and Lifestyle Research Institute, Ottawa

26. Brawley L, Culos-Reed N, Angoen J, Hoffman-Goetz J (2003) Understanding the barriers to physical activity for cancer patients. J Psychol Oncol 20(4):1-21

27. Bandura A (1998) Health promotion from the perspective of social cognitive theory. Psychol Health 13:623-649

28. Sallis JF, Bauman A, Pratt M (1998) Environmental and policy interventions to promote physical activity. Am J Prev Med 15(4): 379-397

29. Andajani-Sutjahjo S, Ball K, Warren N, Inglis V, Crawford D (2004) Perceived personal, social and environmental barriers to weight maintenance among young women: a community survey. Int $\mathrm{J}$ Behav Nutr Phys Act 1(1):15

30. Nies MA, Vollman M, Cook T (1999) African American women's experiences with physical activity in their daily lives. Public Health Nurs 16(1):23-26

31. Popkin BM, Duffey K, Gordon-Larsen P (2005) Environmental influences on food choice, physical activity and energy balance. Physiol Behav 86(5):603-613

32. Pucher J, Buehler R, Seinen M (2011) Bicycling renaissance in North America? An update and re-appraisal of cycling trends and policies. Transp Res A Policy Pract 45(6):451-457

33. Chan CB, Ryan DA (2009) Assessing the effects of weather conditions on physical activity participation using objective measures. Int $\mathrm{J}$ Environ Res Publ Health 6(10):2639-2654

34. Crombie IK, Irvine L, Williams B, McGinnis AR, Slane PW, Alder EM, McMurdo ME (2004) Why older people do not participate in leisure time physical activity: a survey of activity levels, beliefs and deterrents. Age Ageing 33(3):287-292

35. Justine M, Azizan A, Hassan V, Salleh Z, Manaf H (2013) Barriers to participation in physical activity and exercise among middle-aged and elderly individuals. Singap Med J 54(10):581-586

36. Hefferon K, Murphy H, McLeod J, Mutrie N, Campbell A (2013) Understanding barriers to exercise implementation 5-year post-breast cancer diagnosis: a large-scale qualitative study. Health Educ Res 28(5):843-856

37. Brunet J, Taran S, Burke S, Sabiston CM (2013) A qualitative exploration of barriers and motivators to physical activity participation in women treated for breast cancer. Disability Rehab, Published online ahead of print: doi: 10.3109/09638288.2013.802378

38. Ottenbacher AJ, Day RS, Taylor WC, Sharma SV, Sloane R, Snyder DC, Kraus WE, Demark-Wahnefried W (2011) Exercise among breast and prostate cancer survivors-what are their barriers? J Cancer Surviv: Res Pract 5(4):413-419

39. Husebo AM, Dyrstad SM, Soreide JA, Bru E (2013) Predicting exercise adherence in cancer patients and survivors: a systematic review and meta-analysis of motivational and behavioural factors. J Clin Nurs 22(1-2):4-21

40. Pardee RL (1990) Motivation Theories of Maslow, Herzberg, McGregor \& McClelland. A Literature review of selected theories dealing with job satisfaction and motivation. In: Educational Resources Information Center (ERIC) 
41. Juarbe T, Turok XP, Perez-Stable EJ (2002) Perceived benefits and barriers to physical activity among older Latina women. West J Nurs Res 24(8):868-886

42. Rasinaho M, Hirvensalo M, Leinonen $R$, Lintunen $T$, Rantanen $T$ (2007) Motives for and barriers to physical activity among older adults with mobility limitations. J Aging Phys Act 15(1):90-102

43. Husebo AM, Karlsen B, Allan H, Soreide JA, Bru E (2014) Factors perceived to influence exercise adherence in women with breast cancer participating in an exercise programme during adjuvant chemotherapy: a focus group study. J Clin Nurs (in press)

44. Braun V, Clarke V (2006) Using thematic analysis in psychology. Qual Res Psychol 3:77-101

45. Creswell JW (2013) Qualitative inquiry \& research design: choosing among five approaches, 3rd edn. Sage Publications, USA

46. Heath GW (2013) Behavioral approaches to physical activity promotion. In: Clinical Exercise Physiology. 3 edn. Edited by Ehrman JK, Gordon, P.M., Visich, P.S., Keteyian, S.J. Champaign, IL: Human Kinetics 29-30

47. Courneya KS, McKenzie DC, Reid RD, Mackey JR, Gelmon K, Friedenreich CM, Ladha AB, Proulx C, Lane K, Vallance JK et al (2008) Barriers to supervised exercise training in a randomized controlled trial of breast cancer patients receiving chemotherapy. Ann Behav Med 35(1):116-122

48. Rogers LQ, Courneya KS, Robbins KT, Malone J, Seiz A, Koch L, Rao K (2008) Physical activity correlates and barriers in head and neck cancer patients. Support Care Cancer 16(1):19-27
49. Costello E, Kafchinski M, Vrazel J, Sullivan P (2011) Motivators, barriers, and beliefs regarding physical activity in an older adult population. J Geriatr Phys Ther 34(3):138-147

50. Barber FD (2012) Social support and physical activity engagement by cancer survivors. Clin J Oncol Nurs 16(3):E84-E98

51. McNeill LH, Kreuter MW, Subramanian SV (2006) Social environment and physical activity: a review of concepts and evidence. Soc Sci Med 63(4):1011-1022

52. Peterson JA, Yates BC, Hertzog M (2008) Heart and soul physical activity program: social support outcomes. Am J Health Behav 32(5): 525-537

53. Resnick B, Luisi D, Vogel A (2008) Testing the Senior Exercise Selfefficacy Project (SESEP) for use with urban dwelling minority older adults. Public Health Nurs 25(3):221-234

54. Hefferon K, Grealy M, Mutrie N (2008) The perceived influence of an exercise class intrevention on the process and outcomes of posttraumatic growth. Ment Health Phys Act 1:32-39

55. Kolden GG, Strauman TJ, Ward A, Kuta J, Woods TE, Schneider KL, Heerey E, Sanborn L, Burt C, Millbrandt L et al (2002) A pilot study of group exercise training (GET) for women with primary breast cancer: feasibility and health benefits. Psycho-Oncology 11(5):447-456

56. McDonough MH, Sabiston CM, Crocker RE (2008) An interpretative phenomenological examination of psychosocial changes among breast cancer survivors in their first season of dragon boating. J Appl Sports Psychol 20:425-440 